\title{
Genetic Divergence in Brinjal (Solanum melongena L.) Genotypes
}

\author{
P. Vindhya Rani, G. Subbi Reddy, M. Rajasekhar and M. Usharani* \\ Horticultural College and Research Institute, Venkataramannagudem, \\ West Godavari 534101, Andhra Pradesh, India
}

*Corresponding author

\section{A B S T R A C T}

\section{Keywords}

Solanum melongena,

Genetic divergence,

D2 statistics,

Clustering, Fruits,

Genotypes, Yield

Article Info

Accepted:

07 June 2019

Available Online:

10 July 2019
Mahalanobis's $\mathrm{D}^{2}$ statistics was used to study genetic divergence for nineteen characters in a collection of forty four brinjal genotypes. The 44 genotypes of brinjal were grouped into seven clusters on the basis of relative magnitude of $\mathrm{D}^{2}$ values. The maximum inter cluster distance was observed between clusters III and VII, while minimum was recorded between clusters III and IV. The maximum contribution towards divergence was from yield per plant and number of fruits per cluster. Considering cluster means and genetic distances, selection of parents from clusters III and VII for hybridization programme would help in achieving novel recombinants.

\section{Introduction}

Brinjal is one of the most important and popular vegetable crop grown throughout the year all over the country. Being primary centre of origin, India has wide range of variability in this crop. Any plant breeding programme needs clear understanding of existing genetic divergence in available population. A knowledge on genetic diversity, its nature and degree is useful for selecting desirable parents from a germplasm for the successful breeding programme. Mahalanobis $\mathrm{D}^{2}$ techniques appears to be a fruitful approach which is based on multivariate analysis and serves to be a good index of estimating genetic diversity (Gadekar et al., 1992). The present study was planned to generate information on genetic diversity present in forty four diverse genotypes of brinjal so as to help the breeder in selecting promising and genetically diverse parents for bringing the desired improvement.

\section{Materials and Methods}

The present investigation was carried out at Horticultural Research Station, Venkataramannagudem, Andhra Pradesh during kharif season. The material consisted of 40 genotypes and four varieties (checks) of brinjal were evaluated in a Randomized Block Design with two replications at a spacing of $75 \mathrm{~cm} \mathrm{x} 60 \mathrm{~cm}$. Suitable agronomic and cultural practices were adopted to obtain good 
phenotypic expression of the characters. The experimental data was collected on 25 characters. Out of these, 19 were quantitative characters viz., plant height, plant spread, number of primary branches per plant, number of secondary branches per plant, number of flowers per inflorescence, number of fruits per cluster, number of fruits per plant, per cent fruit set of long, medium, short and pseudo short styled flowers, fruit length, fruit diameter, fruit weight, days to first picking, total number of harvests, fruit yield per plant, crop duration and fruit yield per hectare and six were morphological characters which include plant growth habit, leaf blade spinyness, fruit calyx spinyness, fruit shape, fruit colour and calyx colour.

The observations were recorded on randomly selected five plants from each genotype in each replication. $\mathrm{D}^{2}$ statistics is used for accessing the genetic divergence between genotypes as suggested by Mahalanobis (1936). On the basis of magnitude of $\mathrm{D}^{2}$ values the genotypes were grouped into different clusters following Ward's method.

\section{Results and Discussion}

Analysis of variance showed highly significant differences among the genotypes for all the traits under study. The 44 genotypes of brinjal were grouped into seven clusters based on $\mathrm{D}^{2}$ values (Table 1 ). Cluster IV was the largest consisting of 23 genotypes followed by cluster III and cluster I consisting of six genotypes each while cluster $\mathrm{V}$ had 4 genotypes, cluster VI and VII with two genotypes each and one genotype in cluster II.

The genotypes exhibited random pattern of distribution into various clusters and the magnitude of $\mathrm{D}^{2}$ values suggested that there was considerable amount of diversity in the germplasm of brinjal indicating that forces such as genetic drift, natural and artificial selection and exchange of genetic material might have played an important role in the diversity of genotypes.

The intra and inter cluster $\mathrm{D}^{2}$ values among 44 genotypes presented in Table 2 revealed that maximum inter cluster distance was observed between cluster III and VII indicated that the genotypes included in these clusters can be used as parents in hybridization programme for higher heterotic hybrids from segregating population, whereas minimum was recorded between clusters III and IV indicated close relationship among the genotypes included in these clusters. Maximum intra cluster distance was observed in cluster IV, while minimum in cluster II. The genotypes from distant clusters III and VII can be used as parents for hybridization for superior hybrids in terms of vegetative and yield characters.

Table.1 Forty four genotypes of brinjal were grouped into below seven clusters

\begin{tabular}{|l|l|l|}
\hline Cluster & No of genotypes & Genotypes \\
\hline I & 6 & EC386589, IC249358, IC261772, IC089949-B, IC112848, EC316280 \\
\hline II & 1 & IC090785 \\
\hline III & 7 & IC099691, IC136377, PSR11891, IC090132, IC112726, IC354651, EC316226 \\
\hline IV & 22 & $\begin{array}{l}\text { IC545919, IC112736, IC112818, IC111066-2, DBT/OR-37, IC111019, } \\
\text { IC332508, EC379244, DBT/072, IC09002, IC354140, IC090931, IC104083, } \\
\text { IC90767, IC090093, IC99712, IC467271, IC090053, IC111428, EC384565, } \\
\text { IC374888, IC305048 }\end{array}$ \\
\hline $\mathbf{V}$ & 4 & IC090867, IMPROVED BHAGYAMATI, IC420590, IC345747 \\
\hline VI & 2 & BHAGYAMATI, ARKA KESAV \\
\hline VII & 2 & IC285140, GULABI \\
\hline
\end{tabular}


Table.2 Average intra and inter cluster $\mathrm{D}^{2}$ and $\mathrm{D}$ values for fourteen characters in 44 germplasm accessions of brinjal

\begin{tabular}{|c|c|c|c|c|c|c|c|}
\hline Cluster & I & II & III & IV & V & VI & VII \\
\hline I & 812.807 & 5472.404 & 6928.105 & 2652.815 & 7183.401 & 21816.560 & 18131.590 \\
\hline II & & 0.000 & 21665.93 & 13023.09 & 12289.07 & 25870.530 & 7692.810 \\
\hline III & & & 1243.923 & 2216.343 & 8043.884 & 19932.640 & 34894.120 \\
\hline IV & & & & 926.824 & 6309.532 & 19563.980 & 26231.220 \\
\hline V & & & & & 946.519 & 5149.387 & 13217.170 \\
\hline VI & & & & & & 848.433 & 15872.090 \\
\hline VII & & & & & & & 650.057 \\
\hline
\end{tabular}

Table.3 Mean values of clusters for nineteen characters in 44 genotypes of brinjal (Wards method)

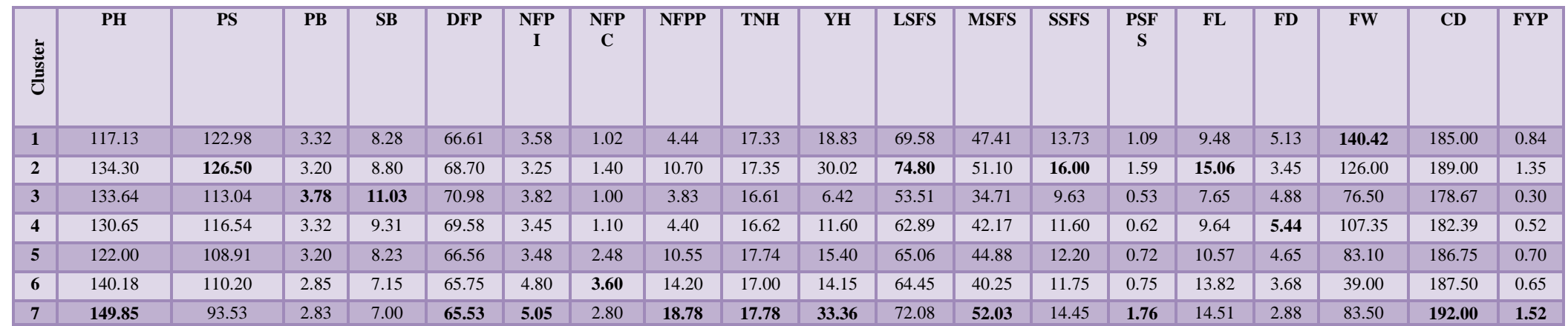

The cluster means of 44 genotypes were presented in Table 3 indicated that cluster means were wider for fruit yield per plant. Cluster I recorded maximum mean value for fruit diameter and fruit weight, while cluster II recorded maximum mean value for plant spread, fruit length, per cent fruit set of long styled flowers and per cent fruit set of short styled flowers. Cluster III recorded maximum mean value for primary and secondary branches per plant, which is superior for growth characters while cluster IV recorded maximum mean value for fruit diameter.

Further, cluster VI recorded maximum mean value for number of fruits per cluster whereas cluster VII recorded maximum mean value for plant height, days to first picking, number of flowers per inflorescence, number of fruits per plant, total number of harvests, yield per hectare, per cent fruit set of medium styled flowers, per cent fruit set of pseudo short styled flowers, crop duration and fruit yield per plant. High cluster mean for most of the yield contributing traits coupled with maximum inter cluster distance was found in cluster III and VII which indicate the superior segregants by inter crossing genotypes from these clusters.

Contribution of different plant characters towards genetic divergence is important for the purpose of further selection and choice of parents for hybridization. Hence selection for divergent parents based on these characters may be useful for exploitation of hybrid vigour in brinjal genotypes. Highest contribution towards divergence was putforth by fruit yield per plant (34.25\%), number of fruits per cluster $(28.96 \%)$ followed by yield per hectare $(13.85 \%)$, number of flowers per inflorescence $(7.19 \%)$, fruit diameter (4.55 
$\%)$ and plant spread (2.64\%). Hence these characters should be given due weightage in formulating brinjal breeding programme. Similar results were reported by Sherly and Shanthi (2007), Das et al., (2010) and Nalini et al., (2011) in brinjal. Selection of divergent parents based on above characters will be used for further breeding programme.

\section{Acknowledgments}

Author thankful to Dr. YSR horticultural university, Tadepalligudem-534101.

\section{References}

Das, S., Mandal, A.B., and Hazra, P. 2010. Genetic diversity in brinjal genotypes under eastern Indian conditions. Indian J. Hort. 67, 166-169.

Gadekar, D.A., Dhonukshe, B. L., and Patil, F. B. 1992. Genetic divergence in tomato. Veg. Sci., 19 (1): 30-35.

Mahalanobis, P.C., 1936. On the generalized distance in statistics. Proceedings of National Institute of Sci. (India) 2, 4955.

Nalini, D.S., Patil, S. A., and Salimath, P. M. 2011. Study on genetic diversity and its relation to heterosis in brinjal (Solanum melongena L.). Karnataka J. Agric. Sci. 24, 110-113.

Sherly, J., and Shanthi, A. 2007. Diversity studies in brinjal. Haryana J. Hortic. Sci. 36, 162-163.

\section{How to cite this article:}

Vindhya Rani, P., G. Subbi Reddy, M. Rajasekhar and Usharani, M. 2019. Genetic Divergence in Brinjal (Solanum melongena L.) Genotypes. Int.J.Curr.Microbiol.App.Sci. 8(07): 571-574. doi: https://doi.org/10.20546/ijcmas.2019.807.070 